\section{SANDIA REPORT}

SAND98-2608

Unlimited Release

Printed December 1998

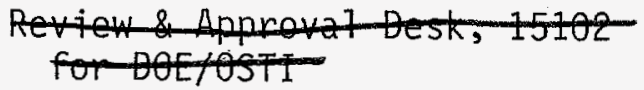

45

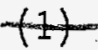

\title{
Catalytic Membrane Sensors
}

Timothy J. Boyle, Timothy J. Gardner, Allen G. Sault, Robert C. Hughes, and C. Jeffrey Brinker

Prepared by

Sandia National Laboratories

Abuquerque, New Mexico 87185 and Livermore, California 94550

Sandia is a nultiprogram laboratory operated by Sandia Corporation, a Lockheed Martin Company, for the United States Department of Energy under Contract DE-AC04-94AL85000.

Approved for public release, further dissemination unlimited.

\section{Sandia National Laboratories}


Issued by Sandia National Laboratories, operated for the United States Department of Energy by Sandia Corporation.

NOTICE: This report was prepared as an account of work sponsored by an agency of the United States Government. Neither the United States Government nor any agency thereof, nor any of their employees, nor any of their contractors, subcontractors, or their employees, makes any warranty, express or implied, or assumes any legal liability or responsibility for the accuracy, completeness, or usefulness of any information, apparatus, product, or process disclosed, or represents that its use would not infringe privately owned rights. Reference herein to any specific commercial product, process, or service by trade name, trademark, manufacturer, or otherwise, does not necessarily constitute or imply its endorsement, recommendation, or favoring by the United States Government, any agency thereof, or any of their contractors or subcontractors. The views and opinions expressed herein do not necessarily state or reflect those of the United States Government, any agency thereof, or any of their contractors.

Printed in the United States of America. This report has been reproduced directly from the best available copy.

Available to $\mathrm{DOE}$ and $\mathrm{DOE}$ contractors from

Office of Scientific and Technical Information

P.O. Box 62

Oak Ridge, TN 37831

Prices available from (615) 576-8401, FTS 626-8401

Available to the public from

National Technical Information Service

U.S. Department of Commerce

5285 Port Royal Rd

Springfield, VA 22161

NTIS price codes

Printed copy: A03

Microfiche copy: A01

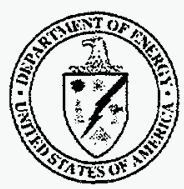




\section{DISCLAIMER}

Portions of this document may be illegible in electronic image products. Images are produced from the best available original document. 
SAND98-2608

Unlimited Release

Printed December 1998

\title{
Catalytic Membrane Sensors
}

\author{
Timothy J. Boyle, \\ Materials Processing Department \\ Timothy J. Gardner and Allen G. Sault \\ New Materials Theory \& Validation Department \\ Robert C. Hughes \\ Microsensor R\&D \\ C. Jeffrey Brinker, \\ Direct Fabrication Technologies \\ Sandia National Laboratories \\ P.O. Box 5800 \\ Albuquerque, NM 87185-1349
}

\begin{abstract}
The proposed "catalytic membrane sensor" (CMS) was developed to generate a device which would selectively identify a specific reagent in a complex mixture of gases. This was to be accomplished by modifying an existing $\mathrm{H}_{2}$ sensor with a series of thin films. Through selectively sieving the desired component from a complex mixture and identifying it by decomposing it into $\mathrm{H}_{2}$ (and other by-products), a $\mathrm{H}_{2}$ sensor could then be used to detect the presence of the select component. The proposed "sandwich-type" modifications involved the deposition of a catalyst layered between two size selective sol-gel layers on a $\mathrm{Pd} / \mathrm{Ni}$ resistive $\mathrm{H}_{2}$ sensor. The role of the catalyst was to convert organic materials to $\mathrm{H}_{2}$ and organic by-products. The role of the membrane() was to impart both chemical specificity by molecular sieving of the analyte and converted product streams, as well as controlling access to the underlying $\mathrm{Pd} / \mathrm{Ni}$ sensor. Ultimately, an array of these CMS elements encompassing different catalysts and membranes were to be developed which would enable improved selectivity and specificity from a complex mixture of organic gases via pattern recognition methodologies. We have successfully generated a CMS device by a series of spin-coat deposited methods; however, it was determined that the high temperature required to activate the catalyst, destroys the sensor.
\end{abstract}




\begin{abstract}
The proposed "catalytic membrane sensor" (CMS) was being developed to generate a device which would selectively identify a specific reagent in a complex mixture of gases. This was to be accomplished by modifying an existing $\mathrm{H}_{2}$ sensor with a series of thin films. Through selectively sieving the desired component from a complex mixture and identifying it by decomposing it into $\mathrm{H}_{2}$ (and other by-products), a $\mathrm{H}_{2}$ sensor could then be used to detect the presence of the select component. The proposed "sandwich-type" modifications involved the deposition of a catalyst layered between two size selective solgel layers on a $\mathrm{Pd} / \mathrm{Ni}$ resistive $\mathrm{H}_{2}$ sensor. The role of the catalyst was to convert organic materials to $\mathrm{H}_{2}$ and organic by-products. The role of the membrane(s) was to impart both chemical specificity by molecular sieving of the analyte and converted product streams, as well as controlling access to the underlying $\mathrm{Pd} / \mathrm{Ni}$ sensor. Ultimately, an array of these CMS elements encompassing different catalysts and membranes were to be developed which would enable improved selectivity and specificity from a complex mixture of organic gases via pattern recognition methodologies. We have successfully generated a CMS device by a series of spin-coat deposited methods; however, it was determined that the high temperature required to activate the catalyst, destroys the sensor.
\end{abstract}




\section{Introduction.}

The attached appendix is a summary of a majority of the work accomplished during the development of the Catalytic Membrane Sensor (CMS) device.' The following sections impart the latest investigations that were undertaken to improve the problems uncovered during the development of the CMS.

Previously a single CMS cell had been successfully generated. Unfortunately, it was determined that the desired operating temperatures of the sensor and the catalysts were significantly different. Alternative catalysts were synthesized and tested for replacement of the NaTi derivatives. Furthermore, different sensor platforms were investigated as replacements for the original $\mathrm{Ni} / \mathrm{Pd}$ resistive sensor. Details regarding these and other aspects of the CMS that were investigated are discussed below.

\section{Synthesis (Tim Boyle).}

Previous investigations (reported in Appendix A) had generated a useful protocol for the production of the CMS sensor and no changes were made in the ensuing investigations. The successful use of $\left[\mathrm{NaTi}(\mathrm{OR})_{5}\right]_{\infty}\left(\mathrm{OR}=\mathrm{OPr}^{\mathrm{i}}, \mathrm{OCHMe}_{2}\right)$ as a "simple" replacement for the standard hydrous titania oxide catalyst (HTO) encouraged us to pursue alternative catalyst sources.

Initial investigations focused on developing catalysts based on the Group IV congener zirconium. One literature compound which appeared promising was the $\mathrm{Na}\left[\mathrm{Zr}_{2}\left(\mathrm{OPr}^{\mathrm{i}}\right) 9\right]$ derivative which was synthesized from $\left[\mathrm{Zr}\left(\mathrm{OPr}^{\mathrm{i}}\right)_{4}\left(\mathrm{HOPr}^{\mathrm{i}}\right)\right]_{2}$ and $\mathrm{NaOPr}^{\mathrm{i}}$ in $\mathrm{HOPr}^{\mathrm{i}}$. An additional alkoxide that was also available for investigation was $[\mathrm{Zr}(\mu-$ $\left.\left.\mathrm{OPr}^{\mathrm{i}}\right)(\mathrm{ONp})_{3}(\mathrm{HONp})\right]_{2}$ which had recently been isolated in our laboratory. This was synthesized from the reaction of $\left[\mathrm{Zr}\left(\mathrm{OPr}^{\mathrm{i}}\right)_{4}\left(\mathrm{HOPr}^{\mathrm{i}}\right)\right]_{2}$ with excess $\mathrm{HONp}(\mathrm{Np}=$ $-\mathrm{CH}_{2} \mathrm{CMe}_{3}$ ) and stirred for a $12 \mathrm{~h}$. period. Derivatization of this compound through the introduction of $\mathrm{NaONp}$ led to the isolation of $\mathrm{NaZr}_{2}(\mathrm{ONp}){ }_{9}(\mathrm{HONp})$. The solution 
behavior of this compound is extremely complicated in comparison to the $\mathrm{OPr}^{\mathrm{i}}$ derivative due to rapid multi-nuclear and multi-ligand inter and intra-exchange; therefore we focused on the "simple" $\mathrm{Na}\left[\mathrm{Zr}_{2}\left(\mathrm{OPr}^{\mathrm{i}}\right)_{9}\right]_{2}$ derivative for initial catalytic investigations (vide infra).

Concurrently during the development of the alkali modified zirconium compounds, we investigated the possibility of synthesizing Rh-containing species which would simplifying the processing scheme of the CMS by eliminating the ion-exchange step for the catalyst layer. The novel precursor solutions that were successfully synthesized consisted of a mixture of $\mathrm{Rh}(\mathrm{acac})_{3}$ and 6 equivalents of $\mathrm{Ti}(\mathrm{OR})_{4}\left(\mathrm{OR}=\mathrm{OCHMe}_{2}\right.$ or $\mathrm{OPr} \mathrm{i} ; \mathrm{OCH}_{2} \mathrm{CMe}_{3}$ or $\mathrm{ONp})$ or $\mathrm{Zr}(\mathrm{OR})_{4}\left(\mathrm{OR}=\mathrm{OCHMe}_{2}\right)$. The two reagents were dissolved in pyridine which resulted in a dark red solution. After stirring for $10 \mathrm{~min}$. the solution was used for production of $M_{6} R h(M=T i, Z r)$ thin films by standard spin-cast methods (3000 rpm / 30 sec.). The films were heated on a hot-plate at $100^{\circ} \mathrm{C}$ to stabilize them during transport for catalytic activity testing. The solution was also dried under vacuum to form a powder which was also tested for catalytic activity. Testing of these materials as a thin film were inconclusive due to the small amount of sample present on the substrate (vide infra).

Membrane (Jeff Brinker). Improved sol-gel based membranes were developed that could be applied to the CMS device and these were investigated. The synthesis and development of this sol referred to as DTS is described below.

The DTS sol-gel was synthesized by the co-polymerization of tetraethoxysilane (TEOS) with dimethyl phosphatethyltriethoxsilane $\left(\left(\mathrm{C}_{2} \mathrm{H}_{5} \mathrm{O}\right)_{2} \mathrm{POCH}_{2} \mathrm{CH}_{2} \mathrm{Si}\left(\mathrm{OCH}_{2} \mathrm{CH}_{3}\right)\right.$ (DTS). In general, a mixture of TEOS and DTS with ethanol, water and $\mathrm{HCl}$ were combined and stirred for $90 \mathrm{~min}$. at $\sim 400 \mathrm{rpm}$. This was then used to generate thin films without further modifications.

This solution produced a highly selective membrane capable of discriminating gas molecules such as $\mathrm{H}_{2}(2.89 \AA), \mathrm{N}_{2}(3.64 \AA), \mathrm{CO}_{2}(3.3 \AA), \mathrm{CH}_{4}(3.8 \AA)$, and $\mathrm{CO}(3.76$ $\AA$ ). In practice, membrane formation was found to be extremely sensitive to the quality of 
the support surface and the film-coating environment. This new procedure resulted in both high flux and selectivity for the membranes with gradual changes of pore size from $50 \AA$ ( $\gamma$-alumina support layer) to $10-12 \AA$ (surfactant-templated silica sublayer), and then to 3 $4 \AA$ (ultramicroporous silica top-layer). For a pure gas permeation experiment, $\mathrm{H}_{2}$ flux reached $1 \times 10^{-3} \mathrm{~cm}^{3}(\mathrm{STP}) / \mathrm{s} / \mathrm{cm}^{2} / \mathrm{cmHg}$ with a $\mathrm{H}_{2} / \mathrm{CO}$ selectivity of 200 . The membrane also showed a high $\mathrm{H}_{2}$ flux $\left(5.4 \times 10^{-4} \mathrm{~cm}^{3}(\mathrm{STP}) / \mathrm{s} / \mathrm{cm}^{2} / \mathrm{cmHg}\right)$ at $80^{\circ} \mathrm{C}$ in the separation of hydrogen from a simulated fuel cell feed stream (compositions: $33.98 \% \mathrm{~N}_{2}, 15.00 \%$ $\mathrm{CO}_{2}, 0.997 \% \mathrm{CO}$, Balance $\mathrm{H}_{2}$ ) as evidenced by a high concentration of hydrogen (92 mol\%) recovered in the permeate side stream.

\section{Catalyst (Tim Gardner).}

POWDERS: We continued to screen bulk catalyst powders in an effort to identify the best candidate materials for thin film catalyst applications within the CMS device. High weight loading hydrous metal oxide- (HMO) and conventional oxide-supported Rh catalysts were evaluated using a known structure-sensitive reaction ( $n$-butane hydrogenolysis). Over a wide range of HMO support compositions, highly dispersed supported Rh catalysts were produced after low temperature activation in $\mathrm{H}_{2}$ as evidenced by high $n$-butane hydrogenolysis activity, high ethane selectivity, and high $\mathrm{H}_{2}$ chemisorptive uptake.

In particular, the ethane selectivity values were significantly higher for the HMOsupported $\mathrm{Rh}$ catalysts than the $\mathrm{TiO}_{2}$ - and $\mathrm{ZrO}_{2}$ - supported $\mathrm{Rh}$ catalysts. For the $\mathrm{TiO}_{2}-$, HTO-, and HTO:Si-supported Rh catalysts, a significant loss of both catalyst activity and $\mathrm{Rh}$ dispersion was observed at more aggressive activation conditions, consistent with $\mathrm{TiO}_{\mathrm{x}}$ migration typically associated with SMSI phenomena. Superior activity and stability were observed for the $\mathrm{ZrO}_{2-}, \mathrm{HZO}-$, and $\mathrm{HZO}: \mathrm{Si}$-supported $\mathrm{Rh}$ catalysts over a wide range of activation conditions in $\mathrm{H}_{2}$. Of all the $\mathrm{Rh} / \mathrm{HMO}$ catalysts, the $\mathrm{Rh} / \mathrm{HZO}$ :Si catalysts appear to offer the best tradeoff in terms of high Rh dispersion, high activity, and high selectivity. The $\mathrm{ZrO}_{2-}, \mathrm{HZO}-$, and $\mathrm{HZO}: \mathrm{Si}$-supported $\mathrm{Rh}$ catalysts are clearly superior to the $\mathrm{TiO}_{2-}$, 
HTO-, and HTO:Si-supported Rh catalysts in terms of activity and stability in higher temperature reducing environments.

This year we successfully extended the Na-Ti double alkoxide chemistry to the $\mathrm{Na}-\mathrm{Zr}$ system $\left(\mathrm{NaZr}_{2}\left(\mathrm{OPr}^{\mathrm{i}}\right)_{9}\right)$. However, unlike the $\mathrm{Na}-\mathrm{Ti}$ double alkoxide, the $\mathrm{Na}-\mathrm{Zr}$ double alkoxide was found to have low $\mathrm{Rh}$ cation exchange capacity. Final $\mathrm{Rh}$ concentrations after cation exchange were $<1 \mathrm{wt} . \%$ for the $\mathrm{Na}-\mathrm{Zr}$ double alkoxide relative to $\sim 8 \mathrm{wt} . \% \mathrm{Rh}$ for the Na-Ti double alkoxide (see 1997 Annual Report). This lack of significant Rh incorporation was judged to be a serious problem with respect to $\mathrm{Rh}$ catalyst preparation using the $\mathrm{Na}-\mathrm{Zr}$ double alkoxide. Due to the low $\mathrm{Rh}$ incorporation level, the final $\mathrm{Rh}$ catalyst precursor synthesized from the $\mathrm{Na}-\mathrm{Zr}$ double alkoxide was not tested using the $n$ butane hydrogenolysis model reaction.

In support of the development of new $\mathrm{Rh}-\mathrm{Ti}$ and $\mathrm{Rh}-\mathrm{Zr}$ double alkoxide materials, we also evaluated the usefulness of $\mathrm{Zr}_{6} \mathrm{Rh}(\mathrm{OR})_{26}$ and $\mathrm{Ti}_{6} \mathrm{Rh}(\mathrm{OR})_{26}$ as supported $\mathrm{Rh}$ catalyst precursors. After dissolution and hydrolysis, the gelatinous precipitate was filtered, washed, dried and analyzed. The dried solid materials revealed by AAS analysis, low $\mathrm{Rh}$ loadings $(<1 \mathrm{wt} . \%)$; therefore, these materials were not tested using the n-butane hydrogenolysis model reaction.

THIN FILM. A reaction test fixture was fabricated to facilitate the $n$-butane hydrogenolysis testing of thin film catalysts supported on a planar geometry (e.g., silicon wafer). Initial tests using $\mathrm{Rh} / \mathrm{HZO}: \mathrm{Si}$ catalyst powder in this fixture showed that for similar catalyst weights, activation conditions, and reaction temperatures, $n$-butane hydrogenolysis activity and selectivity were very similar to those observed in the microreactor used for bulk catalyst testing. However, it became apparent that for small quantities of bulk catalyst powder ( $<5 \mathrm{mg}$ ), it was difficult to detect significant $n$-butane hydrogenolysis product formation (e.g., methane, ethane, and propane) due to the large reactor volume. This necessitated running the $n$-butane hydrogenolysis model reaction at 
temperatures up to $300-350{ }^{\circ} \mathrm{C}$ relative to those used in the bulk catalyst testing microreactor (typically $150-200^{\circ} \mathrm{C}$ ).

The amount of double alkoxide or HMO ion exchanger coating deposited onto plain or A2**-coated silicon wafers was extremely small, typically less than $1 \mathrm{mg}$ and therefore, the ion exchanged $\mathrm{Rh}$ contents of these wafers were expected to be less than $0.1 \mathrm{mg}$. This invalidates any conclusions regarding the activity differences between these various samples. However, one conclusion that could be made was that the plain or $\mathrm{A} 2 * *$-coated silicon wafers contained insufficient porosity and specific surface area to disperse a suitable amount of a thin film catalyst. The combination of insufficient catalyst quantities within the thin film geometry and the large increases in reaction temperature required to observed measurable product formation made this configuration unsuitable for the relatively low temperature $\mathrm{Pd}-\mathrm{Ni} \mathrm{H}_{2}$ sensor platform requirements.

\section{Sensor (Bob Hughes).}

In a continuation of the discovery that the sol-gel layers protected the sensor from poisoning by $\mathrm{H}_{2} \mathrm{~S}$, we investigated different sol-gel coatings under identical conditions. The A2** sol was compared to the DTS as a protection layer against poisoning of the $\mathrm{Pd} / \mathrm{Ni}$-based hydrogen sensor. The coated sensors displayed similar protection against $\mathrm{H}_{2} \mathrm{~S}$ atmospheres.

We were eager to discern if the sol-gel membrane would affect the $\mathrm{H}_{2}-\mathrm{O}_{2}$ reaction at low concentrations of $\mathrm{H}_{2}$. This is not possible with the resistor-sensor because the signal is too small at low $\mathrm{H}_{2}$ concentrations. The companion sensor is a field effect device (capacitor, diode, or transistor) that uses the same $\mathrm{Pd} / \mathrm{Ni}$ films as a field plate. Unfortunately, it is not possible to use the standard adhesion layers since they will effectively screen the field plate catalytic metal and obscure the $\mathrm{H}_{2}$ signal. The field effect devices are capable of giving a signal with only a few ppm of $\mathrm{H}_{2}$ in the presence of $20 \%$ $\mathrm{O}_{2}$. A platform we had on hand, referred to as the "robust sensor" - a sensor (now 
commercially available) with heaters, temperature sensors and both kinds of catalytic metal sensors on one small silicon die - was therefore tested. The robust sensors was coated in a similar manner as reported for the Pd/Ni-based hydrogen sensor; however, it showed significant failure upon subsequent testing. Investigation by optical microscopy indicated that the sol-gel layer was peeling away from the sensors with the FET's and resistor's metal traces embedded in the sol-gel (i.e., it broke the traces in many places and pulled them off the $\mathrm{SiO}_{2}$ surface). A few of the WRS sol-gel coated devices appeared more durable (due to $\mathrm{Ti}$ adhesion layer), but a uniform coating could not be observed. Adjustments are required to improve the coating of the Sandia Robust Sensor or else a new kind of adhesion layer will have to be developed.

\section{Conclusion.}

In conclusion, in this three year project we have demonstrated the feasibility of synthesizing a CMS component. Testing of this device was not possible for two reasons: (i) the sensor platform could not withstand the high temperatures required to utilize the catalyst efficiently and (ii) the operating temperature of the catalyst could not be lowered sufficiently to maintain a usable sensor platform. The investigation of alternative platforms were being pursued at the end of the project.

During this project several new concepts and ideas were produced. The most promising concept was the use of sol-gel coatings as protection against poisoning of the sensor surface. Several sol-gel coatings were being investigated as poison control agents. The use of $\mathrm{Zr}-\mathrm{Rh}$ catalysts in place of the standard Ti-Rh catalysts were being investigated and may prove to possess higher turnover rates in comparison.

A patent application was filed on the basic CMS component and the poison protection ability of the A2** coating. Four presentations ( 2 Posters and 2 talks) and five papers (one invited) concerning the CMS device and the results of the various investigations undertaken were disseminated during this project. 


\section{Papers:}

(1) T. J. Boyle, T. J. Gardner, R. C. Hughes, C. J. Brinker, and A. G. Sault "Catalytic Membrane Sensors. A Thin Film Modified $\mathrm{H}_{2}$ Resistive Sensor for Multi- Molecular Detection" Comments on Inorganic Chemistry - Invited, 1998 (in Press).

(2) T. J. Boyle, J. J. Gallegos, D. M. Pedrotty, E. R. Mechenbier, B. L. Scott "HeteroAlkoxide Group (IV) and (V) Neo-Pentoxide compounds. Syntheses, Characterizations, and X-Ray Structures of $\left[\mathrm{Zr}\left(\mu-\mathrm{OCHMe}_{2}\left(\mathrm{OCH}_{2} \mathrm{CMe}_{3}\right)_{3}\right.\right.$ $\left.\left(\mathrm{HOCH}_{2} \mathrm{CMe}_{3}\right)\right]_{2}$ and $\left[\left(\mathrm{Ta}\left(\mu-\mathrm{OCH}_{2} \mathrm{Me}\right)\left(\mathrm{OCH}_{2} \mathrm{CMe}_{3}\right)_{4}\right]_{2} " J\right.$. Coord. Chem. 1998 (in Press).

(3) C. -Y. Tsai and C. J. Brinker, "Silica Gas Separation membranes Prepared with Surfactant-Templated Sublayers," in Proceedings of the Fifth International Conference on Inorganic Membranes, Nagoya, Japan, June 22-26 (1998) pp.180183.

(4) T. J. Gardner, L. I. McLaughlin, L. R. Evans, and A. K. Datye, "Preparation and Evaluation of Novel Hydrous Metal Oxide (HMO)-Supported Noble Metal Catalysts," Studies in Surface Science and Catalysis, 118 (1998), pp. 245-254.

(5) R. C. Hughes, S. V. Patel, M. W. Jenkins, T. J. Boyle, T. J. Gardner, and C. J. Brinker "Thin Film Porous Membranes based on Sol-Gel Chemistry for Catalytic Sensors". Technical Digest of the Seventh International Meeting on Chemical Sensors, July 27-30, 1998, Beijing, China , 1998, p 41. 


\section{Appendix A}

CATALYTIC MEMBRANE SENSORS. A THIN FILM MODIFIED $\mathrm{H}_{2}$ RESISTIVE SENSOR FOR MULTI-MOLECULAR DETECTION

by:

Timothy J. Boyle, Timothy J. Gardner, Robert C. Hughes, C. Jeffrey Brinker, and Allen G. Sault

Comments on Inorganic Chemistry, 1999. 


\title{
Catalytic Membrane Sensors. a Thin Film Modified $\mathrm{H}_{2}$ Resistive Sensor for Multi-Molecular Detection
}

\author{
TIMOTHY J. BOYLE* and C. JEFFREY BRINKER \\ Sandia National Laboratories, \\ Advanced Materials Laboratory, \\ $100 I$ University Boulevard SE, \\ Albuquerque, New Mexico 87106.
}

TIMOTHY J. GARDNER and ALLEN G. SAULT Sandia National Laboratories - M.S. 0710, P.O. Box 5800, Albuquerque, NM 87185,

and ROBERT C. HUGHES Sandia National Laboratories - M.S. 1425 , P.O. Box 5800, Albuquerque, NM 87185

(Received 02 April, 1998)

A so-called "catalytic membrane sensor" (CMS) is being developed to impart selectivity and reactivity to the surface of an existing sensor by modifying it with a series of thin films. The proposed "sandwich-type" modification involves deposition of a catalyst layer between two size selective sol-gel layers on a Pd/Ni resistive $\mathrm{H}_{2}$ sensor. The role of the catalyst is to convert organic materials to $\mathrm{H}_{2}$ and organic by-products by a dehydrogenation mechanism. The roles of the membranes are to impart chemical specificity by molecular sieving of the anaiyte and the converted product streams as well as to control access to the underlying Pd/Ni sensor. The "sandwich" modification will mediate the sensor response and avoid potential poisoning effects. Ultimately, an array of these CMS ele-

* Author to whom correspondences should be sent.

Comments Inorg. Chem.

1998, Vol. 00, No. 00, pp. 1-23

Reprints available direculy from the publisher

Photocopying perminted by license only
1998 OPA (Overseas Publishers Association) N.V. Published by lieense under the Gordon and Breach Science Publishers imprint. Printed in India


ments encompassing different catalysts and membranes will further enable improvements in selectivity and specificity via pattern recognition methodologies. This report details the synthesis of the various thin film solutions (i.e., catalyst precursors, sol-gel solution), the generation of the catalyst through ion-exchange, a comparison of the double alkoxide versus standard catalyst precursors, and the processing required to generate a CMS. This paper also details the novel and supprising experimental data conceming the increased selectivity and durability observed for the sol-gel modified $\mathrm{H}_{2}$ gas sensing resistors. The utility of the CMS component as a multi-molecular detector will be reported later.

\section{INTRODUCTION}

There continues to be significant interest in increasing the sensitivity of existing sensors while maintaining or even reducing their size. We are developing a method termed a catalytic membrane-based sensor (CMS) that addresses this problem. The CMS modification of an existing sensor will be accomplished through the integration of a Sandia National Laboratories developed Pd/Ni-based hydrogen sensor ${ }^{1,2}$ with size selective gas separation membranes ${ }^{3-5}$ and ion-exchangeable hydrous metal oxide catalyst support ${ }^{6-9}$ overlayers. The basic constructs of the CMS are a catalyst layer, sandwiched between a top and bottom porous thin film $\mathrm{SiO}_{2}$ membrane, deposited on a chemical sensor surface (Figure 1). The role of the catalyst is to convert organic materials to $\mathrm{H}_{2}$ and organic by-products through dehydrogenation reactions. The roles of the membranes are to impart chemical specificity by molecular sieving of the analyte and the converted product streams as well as to control access to the underlying $\mathrm{Pd} / \mathrm{Ni}$ sensor. This will mediate the sensor response and avoid potential poisoning effects. The actual CMS component has only been produced recently; therefore, this paper will only discuss the results obtained in production of the CMS component. Later reports will discuss the utility of the CMS modified sensor as a multi-molecular detection unit.

To produce the CMS prototype it was necessary to understand and develop new processing routes using sol-gel derived materials, ${ }^{3-5}$ synthesize nove ${ }^{10}$ and standard ${ }^{9}$ catalysts from hydrous titanium oxide (HTO) precursor solutions followed by ion-exchange, and testing of the functionality of the sensor at each interval. An existing high quality $\mathrm{Pd} / \mathrm{Ni}_{2}$ resistive sensor was used as the platform to demonstrate the basic concepts of the CMS approach. ${ }^{11}$ The sol-gel layers used in this 


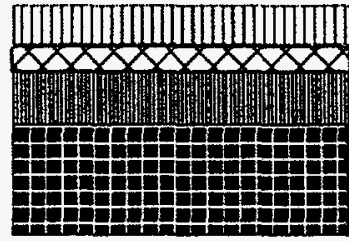

(a) Schematic of a CMS

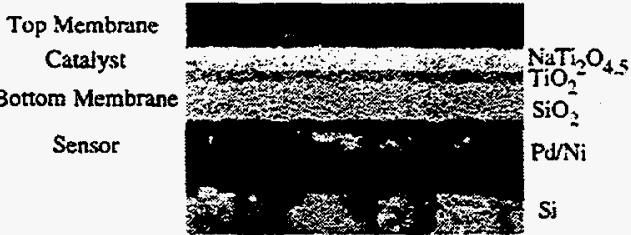

(b) TEM micrograph of actual modified sensor blank.

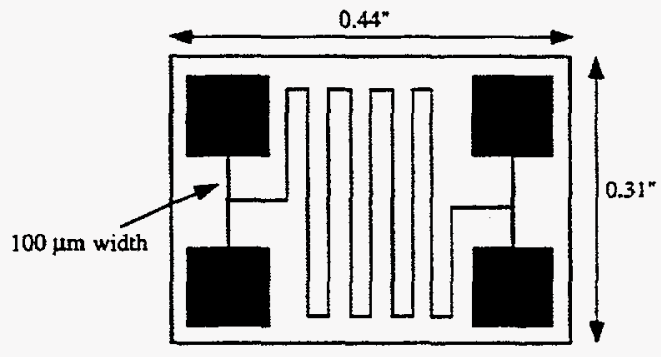

(c) Schematic of the sensor platform (piane view)

FIGURE 1 (a) Diagram of the basic constructs of a CMS component, (b) TEM micrograph of actual CMS component, (c) basic sensor design

project have been extensively studied at Sandia and little modification was required from literature reports. ${ }^{3,4}$ For the catalyst layer, we have isolated and characterized by $\mathrm{X}$-ray crystallography several alkali metal alkoxides of general formula $\left[A T i(O R)_{5}\right]_{n}\left(A=L i, N a, K ; O R=O P r^{i}\right.$ $\left.\left(\mathrm{OCHMe}_{2}\right),{ }^{10} \mathrm{ONp}\left(\mathrm{OCH}_{2} \mathrm{CMe}_{3}\right)^{12}\right)$. The redissolved $\left[\mathrm{NaTi}\left(\mathrm{OPr}^{\mathrm{j}}\right)_{5}\right]_{\infty}$ material was spincast deposited as a thin film and used for ion-exchange to generate a titania-supported $\mathrm{Rh}$ thin film catalyst. Since it is important to know the effect of each film on the sensor's ability to detect $\mathrm{H}_{2}$, we have investigated the sensor's $\mathrm{H}_{2}$ response after each layer was added. The syntheses of various double alkoxide precursors, processing conditions of the spin-coat deposited films and the effect these layers have on the sensor's response will be reported. 


\section{EXPERIMENTAL}

All compounds described below were handled with rigorous exclusion of air and water using standard Schlenk line and glove box techniques unless otherwise noted. The following solvents were distilled immediately prior to use: pyridine from $\mathrm{CaO}$; $\mathrm{THF}$, toluene, and hexanes from $\mathrm{Na}$ /benzophenone. The AOR compounds $\left[\mathrm{A}=\mathrm{Li}, \mathrm{Na}, \mathrm{K} ; \mathrm{OR}=\mathrm{OPr}^{\mathrm{i}}\right.$, ONp] were isolated from the reaction of the appropriate $A H$ and HOR in toluene and purified by sublimation. ${ }^{10,12}$

\section{Sensor Platform}

The basic sensor investigated was a thin film meander line resistor of a $\mathrm{Pd} / \mathrm{Ni}$ alloy which has previously been reported for use as a molecular hydrogen sensor under a wide range of partial pressures. ${ }^{1,2}$ The catalytic films were deposited through a shadow mask on device grade SiN on a Si wafer using a dual e-beam evaporator. The films were $100 \mathrm{~nm}$ thick and had 10 at. $\% \mathrm{Ni}$. An adhesion layer of Ti metal $(10 \mathrm{~nm})$ was used to increase the durability of the sensor. The substrate temperature was maintained at room temperature during the deposition at pressures $<2 \times$ $10^{-6}$ Torr. The devices were annealed in a tube furnace using $2 \% \mathrm{H}_{2}$ in $\mathrm{N}_{2}$ for $2 \mathrm{~h}$ at $350^{\circ} \mathrm{C}$.

The mask design has four pads in the comers of a $1 \mathrm{~cm}^{2}$ chip which were used for a four terminal resistance measurement. The design that was used is shown in Figure 1c. The spring loaded pogo pins that were used in this setup do not require wire bonding to obtain reliable resistance readings of the sensor films. Furthermore, the sensor could be removed and other processing performed (i.e., annealing or microscopy) without having to break any permanent electrical connections.

Adaptation of the silica-based membranes (vide infra) to the $\mathrm{Pd} / \mathrm{Ni}$ sensor surfaces required development of a rigorous surface treatment procedure needed to both degrease the surface and remove a layer of residual oxide. This involved the following steps: (a) soap and water wash, (b) water rinse, (c) soaking in boiling acetone, (d) a water rinse with a nitrogen dry, (e) UV/ozone for 30 minutes at $-20^{\circ} \mathrm{C}$ and (f) hydrogen anneal for 2 hours at $-350^{\circ} \mathrm{C}$. 
Layer 1 and layer 3

\section{Silica Sol-Gel $(A 2 * *)^{3-5}$}

The synthesis of the inorganic membrane consisted of a two step acid catalyzed hydrolysis of $\mathrm{Si}(\mathrm{OEt})_{4}\left(\mathrm{OEt}=\mathrm{OCH}_{2} \mathrm{CH}_{3}\right)$ which was reacted with $\mathrm{HCl} / \mathrm{H}_{2} \mathrm{O}$ in $\mathrm{HOEt}$, followed by heating and additional $\mathrm{HCl} / \mathrm{H}_{2} \mathrm{O}$ additions. The final solution was referred to as $\mathrm{A} 2 * *$ and used for both layers 1 and 3. For layer 1 only, $\mathrm{Ti}\left(\mathrm{OPr}^{\mathrm{j}}\right)_{4}$ was layered on top of the A2** film to decrease pore size and therefore increase selectivity (referred to as $\mathrm{A} 2 * * / \mathrm{Ti}) .^{5} \mathrm{~A}$ more detailed description of the synthesis and processing conditions of $\mathrm{A} 2 * * 3.4$ and $\mathrm{A} 2 * * / \mathrm{Ti}^{5}$ can be found elsewhere.

Layer 2. Hydrous titanium oxide (HTO)

\section{Standard ${ }^{9}$}

To prepare standard bulk HTO ion-exchanger (referred to as ST-HTO) materials, $\mathrm{NaOH}$ was dissolved in $\mathrm{MeOH}(\sim 10 \mathrm{wt} . \% \mathrm{NaOH}$ solution), followed by addition of $\mathrm{Ti}\left(\mathrm{OPr}^{\mathrm{i}}\right)_{4}$. The solution was stirred for $10 \mathrm{~min}$. and then poured into an acetone/water mixture whereupon a precipitate of an amorphous sodium titanate HTO ion-exchanger immediately forms. The resultant powder was washed with more acetone and dried at room temperature under vacuum $(75-130 \mathrm{mmHg})$ and used without further modification.

Synthesis of [ATi(OR) $\left.)_{5}\right]_{n},\left(O R=\operatorname{OPr}^{i}\{A=L i, n=2 ; N a, n=\infty \mathrm{K}\right.$, $n=\infty\}, O N p\{A=L i, n=2 ; N a, n=2 K, n=2\})$

The alkali metal derivative of $\mathrm{Ti}\left(\mathrm{OPr}^{\mathrm{i}}\right)_{4}{ }^{10}$ and $\mathrm{Ti}(\mathrm{ONp})_{4}{ }^{12,13}$ were prepared according to literature reports. The general synthesis involved the dissolution of $\mathrm{Ti}(\mathrm{OR})_{4}$ in toluene which was then mixed with the appropriate alkali alkoxide powder. After stiring for 12 hours, all of the volatile material was removed by rotary evaporation. Crystals of $\left[\mathrm{ATi}\left(\mathrm{OPr}^{\mathrm{i}}\right)_{5}\right]_{\infty}$ were formed by rapid cooling of the reaction mixture. ${ }^{10,14}$ Crystals of $\left[\mathrm{ATi}(\mathrm{ONp})_{5}\right]_{2}$ were obtained by extraction with hot toluene and slow cooling. ${ }^{12,15}$ Approximate $5 \% \mathrm{w} / \mathrm{w}$ solutions of $\left[\mathrm{NaTi}\left(\mathrm{OP}^{\mathrm{j}}\right)_{5}\right]_{\infty}$ in THF were generated and used as stock solutions (referred to as DA-HTO) to produce catalyst precursor films. 


\section{Double Alkoxides}

To prepare bulk HTO ion-exchangers from DA-HTO materials, $5 \mathrm{~g}$ of the $\left[\mathrm{NaTi}(\mathrm{OR})_{5}\right]_{\infty}$ (vide supra) were dissolved in $33.5 \mathrm{~g}$ of $\mathrm{HOPr}^{i}$ and hydrolyzed by pouring the resultant solution into a mixture of $2 \mathrm{~mL}$ $\mathrm{H}_{2} \mathrm{O}$ in $20 \mathrm{~mL}$ of acetone. This results in the precipitation of the HTO ion-exchanger. After washing with acetone, the resultant powder was dried at room temperature under vacuum $(75-130 \mathrm{mmHg})$ and used without further modifications.

\section{Ion-Exchange of Bulk and Thin Films}

Ion-exchange of $\mathrm{Rh}^{+3}$ was achieved by first acidifying an $\mathrm{HTO} / \mathrm{H}_{2} \mathrm{O}$ slurry (nominally $1 \mathrm{~g}$ of the HTO precipitate: $10 \mathrm{~mL} \mathrm{DI} \mathrm{H}_{2} \mathrm{O}$ ) to $\mathrm{pH} 4$ using $10 \mathrm{wt} . \% \mathrm{HNO}_{3}$, resulting in the exchange of a significant portion of $\mathrm{Na}^{+}$with $\mathrm{H}^{+}$. Subsequently, to prepare high weight loading ( $\geq 5.0$ wt.\% $\mathrm{Rh}$ ) $\mathrm{Rh} / \mathrm{HTO}$ samples, a concentrated $(-10 \mathrm{wt} . \% \mathrm{Rh}) \mathrm{Rh}\left(\mathrm{NO}_{3}\right)_{3}$ solution was added in small (1-2 mL) aliquots to affect $\mathrm{Rh}^{+3}$ ion-exchange with $\mathrm{H}^{+}$or $\mathrm{Na}^{+}$. In the standard technique, enough $\mathrm{Rh}\left(\mathrm{NO}_{3}\right)_{3}$ was added to ensure a $50 \%$ excess beyond the total cation exchange capacity of the HTO, assuming exchange of one $\mathrm{Rh}^{+3}$ cation for three $\mathrm{Na}^{+}$ions on the HTO surface. Because of the extreme acidic nature (4-6 $\mathrm{M}$ excess $\mathrm{HNO}_{3}$ ) of the concentrated $\mathrm{Rh}\left(\mathrm{NO}_{3}\right)_{3}$ solution $(\mathrm{pH}<1)$, small $(1-2 \mathrm{~mL})$ additions of $0.6 \mathrm{M} \mathrm{NaOH}$ were required between aliquots to renurn the nominal slurry $\mathrm{pH}$ to the optimum value of $\sim 4$. After completing the addition of the $\mathrm{Rh}\left(\mathrm{NO}_{3}\right)_{3}$, the reaction mixture was stirred for $1 \mathrm{~h}$. at $\mathrm{pH} 4$ (maintained by $\mathrm{NaOH}$ additions) to facilitate complete ion-exchange. This $\mathrm{pH}$ level was chosen to maximize the cation exchange capacity of the HTO support while avoiding precipitation of $\mathrm{Rh}(\mathrm{OH})_{3}$, which occurs at $\mathrm{pH}$ values $>4.5 .^{16}$ After washing (with $\mathrm{H}_{2} \mathrm{O}$ and acetone) and filtering, the catalyst was dried at room temperature under vacuum $(75-130 \mathrm{~mm} \mathrm{Hg}$ absolute pressure) for a minimum of $16 \mathrm{~h}$.

\section{Films}

Films were either generated by standard dip- or spin-coating processes. ${ }^{17}$ Spin coating methods are the preferred technique due to the uniformity of the final films; however, acceptable films were also prepared 
by standard dip-coating methodologies. Using ellipsometric analysis the appropriate spin speed and times to generate a $1000 \AA$ film were determined to be $4000 \mathrm{rpm} / 30 \mathrm{~s}$. It was further found that the devices needed to be placed on a larger wafer to eliminate edge effects. The $\mathrm{A} 2 * * / \mathrm{Ti}$ membrane coatings on the sensor were thermally treated under an $\mathrm{H}_{2} / \mathrm{Ar}$ gas mixture at $250^{\circ} \mathrm{C}$ following the $\mathrm{A} 2 * *$ layer deposition and $100^{\circ} \mathrm{C}$ following the $\mathrm{Ti}\left(\mathrm{OPr}^{j}\right)_{4}$ modification. All of the porous coatings that have been tested, pass molecular hydrogen easily without poisoning of the sensor. The optimal processing temperature (i.e., the highest degree of gas separation) for $\mathrm{H}_{2}$ selectivity was found to be $250^{\circ} \mathrm{C}$ (heating performed externally of the sensor testing chamber). Further testing to determine the failure temperature of the coated sensor revealed that $500^{\circ} \mathrm{C}$ was the upper limit; however, due to the setup of the testing chamber the actual sensor test can only be performed at $300^{\circ} \mathrm{C}$. Catalyst Precursor. A $5 \mathrm{w} / \mathrm{w} \%$ solution of $\left[\mathrm{NaTi}\left(\mathrm{OPr}_{\mathrm{i}}\right)_{5}\right]_{\infty}$ in THF was syringed onto a treated $\mathrm{A} 2 * * / \mathrm{Ti}$ modified sensor. This was allowed to sit for 5 minutes before spinning at $3000 \mathrm{rpm}$ for $30 \mathrm{sec}$. This film was then ion-exchanged with $\mathrm{Rh}$ as described above and heated to $250^{\circ} \mathrm{C}$. Top Layer. To the treated titania-supported $\mathrm{Rh}$ thin film catalyst another A2** layer was spin cast deposited and fired at $100^{\circ} \mathrm{C}$ under $\mathrm{H}_{2} / \mathrm{Ar}$ as before.

Testing

The sensors were mounted in a fixture such that up to six sensors could be exposed to gas mixtures at the same time and their four terminal resistances could be sequentially measured. The fixture was placed in an oven, (maintained at any temperature between $25^{\circ} \mathrm{C}$ to $110^{\circ} \mathrm{C}$ ) which was inside a large hood so that toxic, explosive and corrosive gases could be studied. The gas flows were kept at one Standard Liter per Minute by a bank of flow controllers. The sensors were tested by pulses of $\mathrm{H}_{2} / \mathrm{N}_{2}$ or other gases so that both the transient and steady state responses could be monitored. 


\section{RESULTS AND DISCUSSIONS}

Whenever possible existing systems were used to minimize the amount of development necessary for the construction of the CMS component. Little discussion on the sol-gel layers ${ }^{3,4}$ or the sensor ${ }^{1,2,11}$ are presented since the majority of this information has been previously published. The preparation of potential and the actual precursors used for the catalyst precursor layer, as well as the conversion to the titania-supported $\mathrm{Rh}$ thin film catalyst are described. A comparison of these new materials with existing hydrous titanium-supported Rh (ST-HTO) catalyst precursor solutions will follow. The final section covers the development of the CMS and the various results garnered from the deposition of the different film layers. The actual utility of the CMS device is currently under investigation.

\section{Synthesis}

Double alkoxides of titanium alkali metals have been known for more than 5 decades; ${ }^{18}$ however, the solid state structures have only been recently been reported (see Figure 2a-c). ${ }^{10}$ It was thought that these would be good replacements for the HTO precursors due to their similar content and relative ease of preparation.

Due to the inherent sensitivity of these double alkoxides to ambient humidity, all synthesis described were handled under an inert atmosphere. Ti $\left(\mathrm{OPr}^{\mathrm{i}}\right)_{4}$ was freshly distilled to remove any potential hydrolysis side products. The alkali metal alkoxide powders "NaOR" are typically prepared from either the reaction of $\mathrm{Na}^{\circ}$ or $\mathrm{NaH}$ and the parent alcohol, in this case HOPr, eq. 1 . Note: This can be a very vigorous reaction and

$$
\mathrm{NaH}+\mathrm{HOCHMe}_{2} \stackrel{\mathrm{HOCHMe}_{2}}{\longrightarrow} \mathrm{NaOCHMe}_{2}
$$

the reaction vessel should be cooled in an ice bath. The resulting white powder was mixed with $\mathrm{Ti}\left(\mathrm{OPr}^{\mathrm{j}}\right)_{4}$ in iso-propanol/toluene at the stoichiometric ratio $(n=1)$ to isolate the desired double alkoxides (eq. 2, Figure 2). These solutions were.converted to a stock

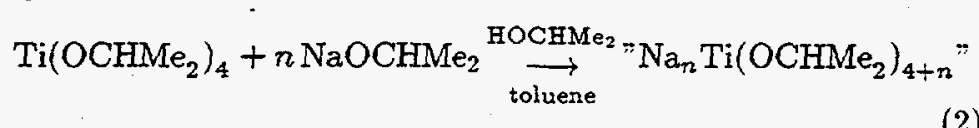


(A)

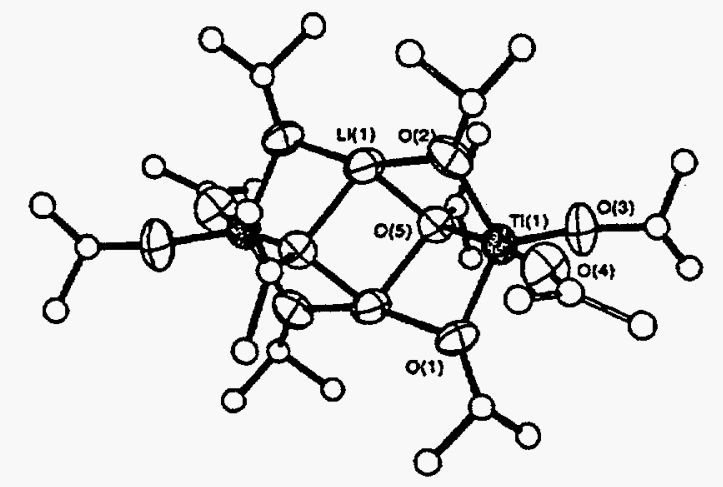

(B)

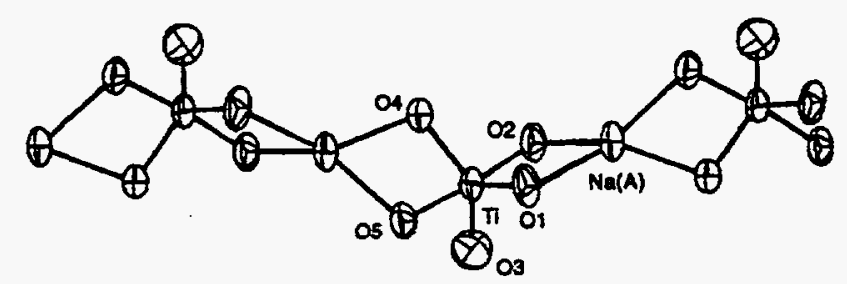

(hydrocarbons omitted)

(c)

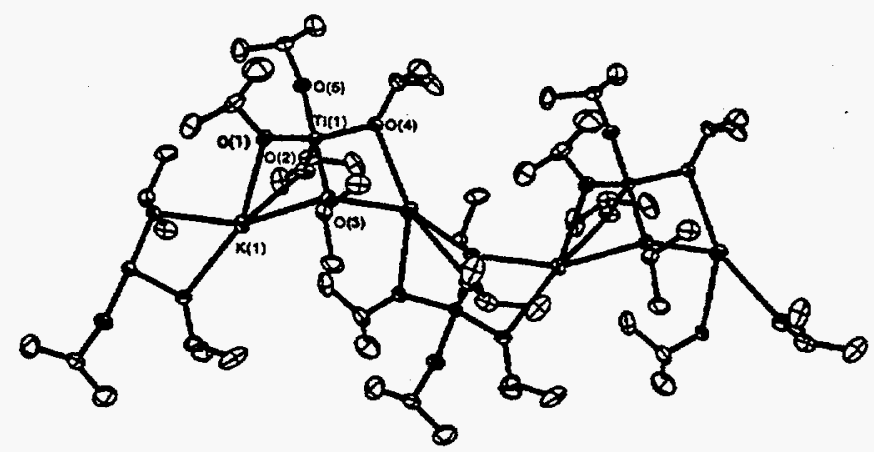

FIGURE 2 Thermal ellipsoid plot of potential catalyst precursor double alkoxides of $\mathrm{Ti}\left(\mathrm{OPr}^{\mathrm{j}}\right)_{4}$ : (a) $\left[\mathrm{LiTi}\left(\mathrm{OPr}^{\mathrm{j}}\right)_{5}\right]_{2}$, (b) $\left[\mathrm{NaTi}\left(\mathrm{OPr}^{\mathrm{i}}\right)_{5}\right]_{\infty}$ (c) $\left[\mathrm{KTi}\left(\mathrm{OPr}^{\mathrm{i}}\right)_{5}\right]_{\infty}$

powder by removal of all of the volatile material and redissolved in THF when HTO precursor solutions were required. These solutions are flexible in the amount and type of alkali metal that can be incorporated and 
are amenable to standard dip coating processes which makes them ideal for generation of the CMS components. The mixed-metal double alkoxide precursor to the catalytic layer is shown in Figure $2 \mathrm{~b}$ and has been previously characterized in the solid state as $\left[\mathrm{NaTi}(\mathrm{OPr})_{5}\right]_{\infty}$; wherein, the alkali metal acts as a bridge between discrete, mononuclear, trigonal-bipyramidal, $\mathrm{Ti}\left(\mathrm{OPr}^{3}\right)_{5}$ moieties. ${ }^{10}$ This material was found to be dinuclear in toluene solutions. ${ }^{14}$ For this study we have concentrated on the $\left[\mathrm{NaTi}\left(\mathrm{OPr}^{\mathrm{j}}\right)_{5}\right]_{\infty}$ complex (DA-HTO) due to its similarity to the ST-HTO catalyst ion-exchange material.

Other alkali metal $\mathrm{OPr}^{\mathrm{j}}$ derivatives have also been isolated as $\left[\mathrm{LiTi}\left(\mathrm{OPr}^{\mathrm{j}}\right)_{5}\right]_{2}$ (Figure 2a) and $\left[\mathrm{KTi}\left(\mathrm{OPr}^{\mathrm{j}}\right)_{5}\right]_{\infty}$ (Figure 2c). ${ }^{10}$ Recently we have isolated a new titanium alkoxide characterized as $\left[\mathrm{Ti}(\mu-\mathrm{ONp})(\mathrm{ONp})_{3}\right]_{2}$ (Figure 3a). ${ }^{13}$ Attempts to generate double alkoxides from this precursor have lead to the isolation of $\left[\mathrm{LiTi}(\mathrm{ONp})_{5}\right]_{2}$ (Figure 3b) and [KTi(ONp) $\left.)_{5}\right]_{2}$ (Figure 3c). ${ }^{12,15}$ Each of these can be utilized as a catalyst precursor. Alternative catalyst precursors are also being investigated including " $\mathrm{AZr}(\mathrm{OR})_{5}$ " (HZN) ion-exchange compounds for higher temperature processing and pre-mixed " $\mathrm{RhTi}_{6}(\mathrm{OR})_{26}$ " or " $\mathrm{RhZ}_{6}(\mathrm{OR})_{26}$ " precursor solutions to eliminate the ion-exchange step. All of the above materials have been generated as films and powders and are currently being investigated/compared to ST-HTO precursors and catalysts.

\section{Catalyst}

Initial work on the double alkoxide catalyst layer has focused on comparing the DA-HTO to the ST-HTO ion-exchange precursors. Ion-exchange experiments, using a $\mathrm{Rh}^{+3}$ controlled ion-exchange procedure, ${ }^{6}$ were performed using three DA-HTO powders (Na:Ti molar ratios of $0.5,1.0$, and 2.0), in addition to a $\mathrm{Na}: \mathrm{Ti}(0.5: 1)$ material prepared using the ST- HTO process (see Experimental Section) to determine the extent of the $\mathrm{Rh}^{+3}$ loading that could be realized. To allow a fair comparison of the various $\mathrm{Na}: \mathrm{Ti}$ stoichiometries prepared in this study, enough $\mathrm{Rh}^{+3}$ was added to ensure a 50\% excess beyond the total cation exchange capacity of the HTO, assuming one $\mathrm{Rh}^{+3}$ cation was exchanged for three $\mathrm{Na}^{+}$ions on the HTO surface. In this manner, it could be determined if the DA-HTO with higher Na:Ti stoichiometries offered any advantages in terms of preparing high metal loading catalyst materials. 


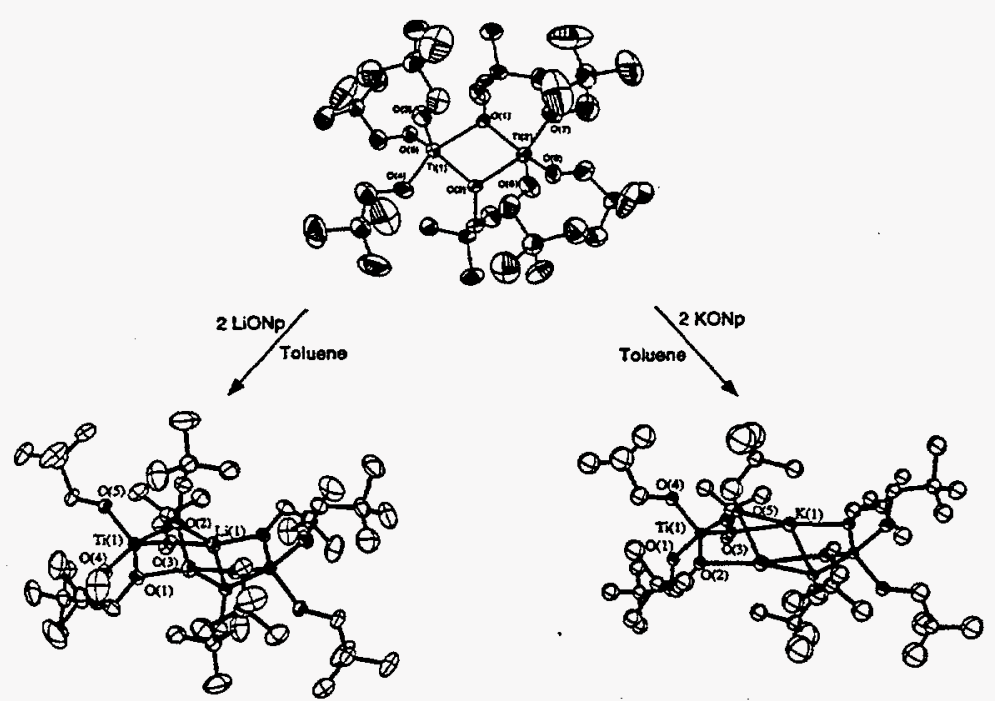

FIGURE 3 Thermal ellipsoid plot of potential catalyst precursor double alkoxides of (a) $\left[\mathrm{Ti}(\mu-\mathrm{ONp})(\mathrm{ONp})_{3}\right]_{2}$, (b) $\left[\mathrm{LiTi}(\mathrm{ONp})_{5}\right]_{2}$, and (c) $\left[\mathrm{KTi}(\mathrm{ONp})_{5}\right]_{2}$

TABLE I Comparison Between Bulk Powders of DA-HTO $\left[\mathrm{Na}_{n} \mathrm{Ti}(\mathrm{OPT})_{4+n}\right]$ and ST-HTO before and after $\mathrm{Rh}^{+3}$ Exchange

\begin{tabular}{|c|c|c|c|}
\hline Na:Ti Ratio ${ }^{a}$ & Initial Wt. $\% N a^{b}$ & $W t \% R h^{c}$ & $W t . \% N a^{c}$ \\
\hline DA-HTO $(0.5)^{\mathrm{a}}$ & 7.85 & 9.75 & 0.03 \\
\hline DA-HTO (1.0) & 13.3 & 7.93 & 0.03 \\
\hline DA-HTO $(2.0)$ & 19.9 & 7.18 & 0.05 \\
\hline ST-HTO $(0.5)$ & 9.10 & 8.50 & 0.04 \\
\hline ST-HZO $(0.5)^{\mathrm{d}}$ & - & 7.28 & 0.04 \\
\hline
\end{tabular}

${ }^{2}$ The number in parentheses refers to the stoichiometry of $\mathrm{Na}$ to $\mathrm{Ti}$ in the initial solution. $100 \%$ incorporation is assumed.

${ }^{\mathrm{b}}$ After bulk HTO synthesis via hydrolysis.

${ }^{\mathcal{C}}$ After controlled $\mathrm{Rh}^{+3}$ ion-exchange procedure (as-prepared basis):

${ }^{d}$ See Ref No. 22.

Atomic absorption spectrometry (AAS) analysis of the precipitated bulk HTO ion-exchangers is shown below in Table I. It is clear from the 
increasing initial wt.\% $\mathrm{Na}$ in the hydrolyzed product with increasing $\mathrm{Na}$ :Ti ratio that the increased $\mathrm{Na}$ levels in the DA-HTO materials have been successfully incorporated into the precipitated bulk HTO ion-exchangers. The data in Table I show that each of the final Rh/HTO catalyst precursor materials has nominally the same $\mathrm{Rh}$ loading, in the range of 7-10 wt.\% on an as-prepared basis, while $\mathrm{Na}$ has been completely removed. The fact that the final $\mathrm{Rh}$ loadings were not significantly higher for the HTO materials with the higher Na:Ti ratios indicates that once a $\mathrm{Na}$ : Ti ratio of 0.5 has been exceeded, the excess $\mathrm{Na}$ is easily exchanged and lost during the acidification process. This fact is consistent with previous work associated with $\mathrm{Ni}^{+2}$ ion-exchange with $\mathrm{Na}_{1.0}$ Ti materials prepared via double alkoxides. ${ }^{19}$

Therefore, blanks (substrates which had identical make-up ( $\mathrm{Pd} / \mathrm{Ni}$ ) as the sensor but without the resistors present) of a thin film of the $\left[\mathrm{NaTi}(\mathrm{OR})_{5}\right]_{\infty}$ double alkoxide were generated by spin coating techniques. A $0.4 \mathrm{M}$ solution of $\left[\mathrm{NaTi}(\mathrm{OR})_{5}\right]_{\infty} / \mathrm{THF}$ onto $\mathrm{Si} / \mathrm{SiO}_{2}$ wafers was used to determine optimal speed and time for generation of the optimal $1000 \AA$ thick films. It was found that films processed in air developed swirls due to the hypersensitivity of the $\left[\mathrm{NaTi}(\mathrm{OR})_{5}\right]_{\infty}$ to ambient atmosphere. Setting up a spinner under inert atmosphere eliminated this problem. The films were successfully ion-exchanged to generate titania-supported $R h$ thin film catalysts. A successfully ion-exchanged $\left[\mathrm{NaTi}(\mathrm{OR})_{5}\right]_{\infty}$ film, on a silicon wafer, was analyzed by XPS, Auger electron spectroscopy (AES), and secondary ion mass spectrometry (SIMS) depth profiling. The surface analysis results are essentially identical with those obtained from analysis of the thin film $\mathrm{Rh} / \mathrm{ST}$-HTO materials. $\mathrm{Rh}$ to $\mathrm{Ti}$ intensity ratios as measured by AES and XPS, as well as $\mathrm{Rh}$ depth distribution as measured by SIMS, all exhibit values in good agreement with those measured for the Rh/ST-HTO films. This agreement strongly supports the proposition that the ion-exchange properties of the NaTi films with respect to $\mathrm{Rh}$ exchange closely mimic those found for HTO films. ${ }^{6}$

To verify this idea, bulk supported $\mathrm{Rh}$ catalyst prepared from both DA-HTO and ST-HTO ion exchangeable supports were tested for catalytic activity using n-butane hydrogenolysis, a known structure-sensitive reaction. ${ }^{20-22}$ The different catalysts (ST-HTO vs. DA-HTO) were examined following two types of activation treatments in $\mathrm{H}_{2}$ (results shown in Table II). First, a low temperature $\left(150^{\circ} \mathrm{C}\right)$ activation treatment was performed, followed by a higher temperature $\left(300^{\circ} \mathrm{C}\right)$ activa- 
tion treatment for various times to monitor changes in catalyst performance. Previous experience with high weight loading $\mathrm{Rh} / \mathrm{ST}$-HTO catalysts has shown that the catalyst activity is optimized for low temperature activation conditions. Increases in activation temperature result in sharp decreases in catalyst activity due to strong metal-support interaction (SMSI) phenomena that cause the formation of reduced $\mathrm{TiO}_{\mathrm{x}}$ species. These molecules migrate to, and block, active sites on the supported metal particles.

TABLE II n-Butane Hydrogenolysis Activity Results for Rh/HTO Catalysts Prepared Using Different Synthesis Techniques

\begin{tabular}{lcccc}
\hline Ion-Exchanger & Wt.\% Rh & $\begin{array}{c}150^{\circ} \mathrm{Cl} \mathrm{H}_{2} \\
\text { Activation } \mathrm{h} h \\
\text { Rate Data }\end{array}$ & $\begin{array}{c}300^{\circ} \mathrm{ClH}_{2} \\
\text { Activation Ih } \\
\text { Rate Data }\end{array}$ & $\begin{array}{c}300^{\circ} \mathrm{Cl} \mathrm{H}_{2} \\
\text { Activation 32 h } \\
\text { Rate Data }\end{array}$ \\
\hline ST-HTO & 8.5 & $0.106(1.243)$ & $1.28 \times 10^{-6}$ & $2.0 \times 10^{-7}$ \\
DA-HTO $(0.5)^{\mathrm{a}}$ & 9.8 & $0.164(1.677)$ & $3.22 \times 10^{-5}$ & $1.2 \times 10^{-6}$ \\
DA-HTO $(1.0)$ & 7.9 & $0.167(2.109)$ & $\mathrm{NA}$ & $\mathrm{NA}$ \\
DA-HTO $(2.0)$ & 7.2 & $0.057(0.789)$ & NA & NA \\
ST-HZO $(0.5)^{\mathrm{c}}$ & 7.3 & $0.050(0.690)$ & $0.1440(1.9778)$ & $0.1202(1.6518)$ \\
\hline
\end{tabular}

${ }^{2}$ The number in parenthesis refers to the stoichiometry $(x)$ of the double alkoxide solution $\left[\mathrm{Na}_{x} \mathrm{Ti}(\mathrm{OR})_{4+x}\right]$

Units for reaction rate data are $\mu$ moles n-butane reacted/(g raw catalyst $\Sigma s$ ). For data included in parentheses, units are mmoles n-butane reacted/( $\mathrm{ghh} \Sigma \mathrm{s}$ ). All reported n-butane hydrogenolysis rates correspond to a reaction temperature of $150^{\circ} \mathrm{C}$. NA $=$ Not applicable. Testing not performed.

'See Ref No. 22

Table II shows that all of the catalysts have relatively high $n$-butane hydrogenolysis activity after low temperature activation. The scatter observed in the data is not statistically significant. Table II also shows the sharp drop-off in catalyst activity upon exposure to higher temperature activation conditions. The large drop in activity (4-6 orders of magnitude) observed for both ion-exchanged catalysts is consistent with the SMSI phenomena described above. From these activity tests, we can conclude that the bulk titania-supported $\mathrm{Rh}$ catalysts derived from the DA-HTO and the ST-HTO precursors behave in a nearly identical manner. The DA-HTO material is 10 times better than the ST-HTO material after a $300^{\circ} \mathrm{C}$ heat treatment (these have been extrapolated from higher 
temperature reaction rate data using calculated Arrhenius parameters). The loss of activity at higher temperatures in the presence of $\mathrm{H}_{2}$ can be avoided by the use of hydrous zirconia (ST-HZO) supports (see Tables I and II). These materials were synthesized in a similar manner as described for the titania supports, wherein $\mathrm{Ti}\left(\mathrm{OPr}^{\mathrm{j}}\right)_{4}$ was replaced with $\mathrm{Zr}(\mathrm{OEt})_{4}$ (details are supplied elsewhere ${ }^{22}$ ).

Sensor

\section{Design}

As mentioned in the introduction a "sandwich" of thin films consisting of a catalyst layer in-between two sol-gel size selective membranes (Figure 1a) is the basic design of the CMS. A multi-layer structure that mimics the intended sensor/membrane/catalyst architecture was prepared by successive sol-gel spin-coat procedures onto a "blank", shown in Figure $1 \mathrm{~b}$. The bottom membrane was prepared by spin-coating a mixture of $\mathrm{A} 2 * *^{3-5}$ onto a cleaned "blank" followed by processing at $250^{\circ} \mathrm{C}$. A Ti $\left(\mathrm{OPr}_{4}\right)_{4}$ layer was then added to further reduce the porosity and heat treated at $250^{\circ} \mathrm{C}$ to generate the first layer $\mathrm{H}_{2}$ selective membrane. ${ }^{5}$ Double alkoxide solutions (vide supra) were generated by spin-coat deposition of the redissolved $\left[\mathrm{NaTi}\left(\mathrm{OPr}^{j}\right)_{5}\right]_{\infty}$ powders in THF followed by an ion-exchange to generate the catalytic layer. ${ }^{20-22}$ The cross-sectional TEM micrograph shown in Figure 1b clearly illustrates the successful integration of the sensor membrane and catalyst layers consistent with the intended idealized microstructure shown in Figure 1. Ion-exchange was successfully undertaken to remove the $\mathrm{Na}$ ions and replace them with $R h$ (3:1 exchange). The ion-exchanged film was heated to $250^{\circ} \mathrm{C}$ to convert the metallo-organic species to the finely divided metallic and ceramic components. Finally the top sol-gel layer was added by spin-coating methods, thereby, completing the "CMS-blank".

After successful generation of the "CMS-blank", a working sensor (Figure 1c) was used as the substrate for film deposition. An identical layering process used to generate the "CMS-blank" was undertaken to produce the working CMS component. Throughout the various layer additions, the sensor was tested to insure that $\mathrm{H}_{2}$ could still be detected. Several unusual and exploitable observations were noted, especially after the first layer was added. 


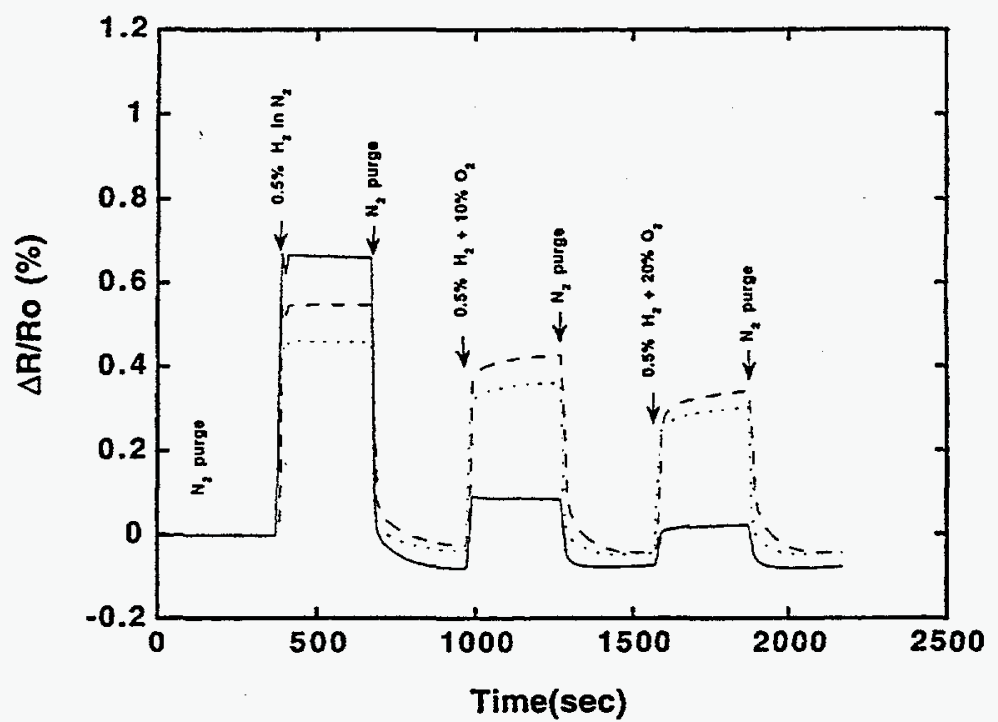

FIGURE 4 The resistance change of three Pd/Ni sensors to pulses of the mixtures indicated. Flow rate is always one SLM, with $\mathrm{N}_{2}$ as the make-up gas. Sensor HTR 16.3 has the silica coating. The sensor temperatures are ail $80^{\circ} \mathrm{C}$ and sensors 16.3 and 9.4 had both received a $150^{\circ} \mathrm{C}$ anneal

Layer $1(\mathrm{~A} 2 * *$ Sol-Gel)

The sol-gel coated $\mathrm{Pd} / \mathrm{Ni}$ resistive hydrogen sensor was annealed from $100^{\circ} \mathrm{C}$ to $400^{\circ} \mathrm{C}$ at $50^{\circ} \mathrm{C}$ intervals, in a $2 \%$ hydrogen ambient atmosphere. The response of an uncoated versus a coated sensor at $50^{\circ} \mathrm{C}$ sensor temperature are shown in Figure 4. The sensor was able to respond to hydrogen gas or mixtures of hydrogen and oxygen gases throughout the various heat treatments. A smaller signal with respect to an uncoated $\mathrm{Pd} / \mathrm{Ni}$ resistor from mixtures of hydrogen and oxygen were measured at anneals between $150-250^{\circ} \mathrm{C}$. At $300^{\circ} \mathrm{C}$, a distinct change in the sol-gel coated sensor's response to both hydrogen and mixtures of hydrogen and oxygen occurs. At the present time, this complex response is not completely understood, but a compression of the pore size in the sol-gel coating is suspect. At anneals higher than $300^{\circ} \mathrm{C}$, the measured signals are similar for both $10 \%$ and $20 \%$ oxygen mixtures with $0.5 \%$ hydrogen. These results show with this arrangement there is significant poten- 
tial for blocking the influence of oxygen with respect to hydrogen and oxygen mixtures and, using different sol-gel solutions, the potential of deriving the individual molecular concentrations in mixtures by pattern recognition.

Characterization of the porosity of membranes deposited on $\mathrm{Pd} / \mathrm{Ni}$ sub-layers was begun using a cantilever beam molecular probe technique developed at Sandia. ${ }^{23,24}$ Briefly, this technique involves measuring the deformation of a very thin wafer coated with a film upon exposure to a series of gases. If there is no intercalation of gas into the film, the bend of the wafer will remain constant. Initial experiments indicated that the membranes processed at $500^{\circ} \mathrm{C}$ had no porosity accessible to water, establishing the pore size as less than about $0.38 \mathrm{~nm}$. TEM experiments performed on similarly processed samples revealed substantial interaction of the $\mathrm{Pd} / \mathrm{Ni}$ and membrane layers consistent with the observed loss in porosity. This idea would be consistent with the destruction of the $\mathrm{Pd} / \mathrm{Ni}$ film observed for the high temperature processed sol-gel modified sensors. Lower temperature $\left(<300^{\circ} \mathrm{C}\right)$ processing revealed intercalation of $\mathrm{H}_{2} \mathrm{O}$ into the film and this was used as the processing temperature for the $\mathrm{A} 2 * *$ films.

\section{$\mathrm{H}_{2} / \mathrm{O}_{2}$ Sensing}

Some interesting behavior in the sensing of hydrogen for the A.** coated sensors was noted when the $\mathrm{H}_{2}$ gas was mixed with other gases. On bare sensor surfaces, $\mathrm{O}_{2}$ competes with $\mathrm{H}_{2}$ for adsorption sites, which usually causes the sensor to give a signal which would be characteristic of a lower partial pressure of $\mathrm{H}_{2}$ in an inert atmosphere (i.e., the sensor detects less $\mathrm{H}_{2}$ ). Little difference in the time response of a coated versus an uncoated sensor was observed. It was thought that the nanoporous coating would reduce the amount of $\mathrm{O}_{2}$ and give an $\mathrm{H}_{2}$ signal independent of $\mathrm{O}_{2}$ partial pressure. This did not occur. Two different partial pressures of $\mathrm{O}_{2}$ were investigated while holding the partial pressure of $\mathrm{H}_{2}$ constant and the results are shown in Figure 4. For the coated sensors, the activity of $\mathrm{O}_{2}$ actually increased as determined by a decrease in the amount of $\mathrm{H}_{2}$ detected; however, it is of note that the $\mathrm{H}_{2}$ signal was not obscured completely. If the very small pores in the $\mathrm{A} 2 * *$ silica reduced the amount of $\mathrm{O}_{2}$ that reached the $\mathrm{Pd} / \mathrm{Ni}$ surface, the resulting $\mathrm{H}_{2}$ signal should be independent of $\mathrm{O}_{2}$ partial pressure. Not only did this not occur, but the amount of $\mathrm{H}_{2}$ signal recorded for the coated sensor is 
smaller than on the uncoated sensors. This indicates that not only are the molecules of $\mathrm{H}_{2}$ and $\mathrm{O}_{2}$ gases being detected but the $\mathrm{O}_{2}$ is preferentially observed. One would expect this result for a very clean $\mathrm{Pd} / \mathrm{Ni}$ catalyst surface as in ultra high vacuum when there is an excess of $\mathrm{O}_{2}$. The $\mathrm{O}_{2}$ is more catalytically active on a clean surface than a contaminated one (relative to $\mathrm{H}_{2}$ ); therefore, in spite of the thick overlayer, the coated sensor acts more like a clean surface! This result was reproducible for many repeated exposures on the same sensor if there were no further high temperature anneals.

Our present explanation of this observation is that it represents a radical example of the "spill-over" effect. ${ }^{25}$ "Spill-over" is said to occur when a catalytic reaction (i.e., $\mathrm{H}_{2}$ and $\mathrm{O}_{2}$ reacting to become $\mathrm{H}_{2} \mathrm{O}$ ) occurs at an atomic location, distant from the catalytic metal atom, in this case Pd. The Pd/Ni resistive sensor does not measure the reaction products directly, but only the equilibrium between the bulk of the $\mathrm{Pd} / \mathrm{Ni}$ film and the metal surface. The word "surface" becomes a little obscure when a $1000 \AA$ sol-gel (or glass) film is strongly bonded to that surface. Nevertheless, the presence of the glass film has little effect on the equilibrium bulk concentration of $\mathrm{H} \bullet$ with the partial pressure of $\mathrm{H}_{2}$ external to the film. It would be difficult to distinguish a coated and uncoated sensor with this experiment. However, when the oxidant $\mathrm{O}_{2}$ is added to the mixture, the difference becomes readily apparent. Glass films annealed at $150^{\circ} \mathrm{C}$ have more $\mathrm{O}_{2}$ catalytic activity than uncoated sensors.

Though unexpected, this result can be exploited through the use of pattern recognition to derive the individual concentrations of $\mathrm{H}_{2}$ and $\mathrm{O}_{2}$ in a mixture where both are unknown. This determination is especially important when explosive mixtures are suspected. For example, a mixture of $4 \% \mathrm{H}_{2}$ and $20 \% \mathrm{O}_{2}$ can be detonated, causing physical damage, whereas a mixture of $3 \% \mathrm{H}_{2}$ and $10 \% \mathrm{O}_{2}$ will burn, but not detonate when an ignition source is present. Thus it is important to have accurate measurements of the concentrations in this range. For much higher concentrations of $\mathrm{H}_{2}(>10 \%)$, the sensor signals are not strongly effected by $\mathrm{O}_{2}$ and the pattem recognition will fail to give accurate results for the $\mathrm{O}_{2}$ concentration. In any case, such high concentrations are very dangerous and should be acted on whether $\mathrm{O}_{2}$ is present or not. For very low $\mathrm{H}_{2}$ concentrations $(<0.1 \%)$ the resistive sensor is not accurate.

A second type of sensor based on the same Pd/Ni type film is called a Field Effect Transistor (FET) sensor ${ }^{26}$ and it will measure partial pres- 
sures of $\mathrm{H}_{2}$ down to as low as 10 parts per million in $20 \% \mathrm{O}_{2}$. In the future we would like to explore FET sensors with the same coatings as reported in the article. These devices are more difficult to fabricate than the resistors reported here, but will be important when molecules that are not detected on uncoated devices and exposed to CMS catalytically active coated sensors.

\section{Poisoning by $\mathrm{H}_{2} \mathrm{~S}$}

In catalytic sensors (e.g., the $\mathrm{Pd} / \mathrm{Ni}$ resistors under discussion), sulfur poisoning is revealed as a slow response to a pulse of $\mathrm{H}_{2}$ of a given partial pressure (but the signal size is not reduced). Due to the interesting response to $\mathrm{H}_{2} / \mathrm{O}_{2}$ mixtures, tests were undertaken to determine the amount of protection the glass film imparts to the $\mathrm{Pd} / \mathrm{Ni}$ surface against poisoning by $\mathrm{H}_{2} \mathrm{~S}$. The results are depicted in Figure 5. Six sensors were tested simultaneously by exposure to $1000 \mathrm{ppm}$ of $\mathrm{H}_{2} \mathrm{~S}$ in $\mathrm{N}_{2}$ at $34^{\circ} \mathrm{C}$ in three separate tests. The coated sensors showed no meaningful change in response upon exposure to the $\mathrm{H}_{2} \mathrm{~S}$ gas under the conditions investigated; however, some of the uncoated sensors failed to detect hydrogen by the third exposure and the other was notably slowed.

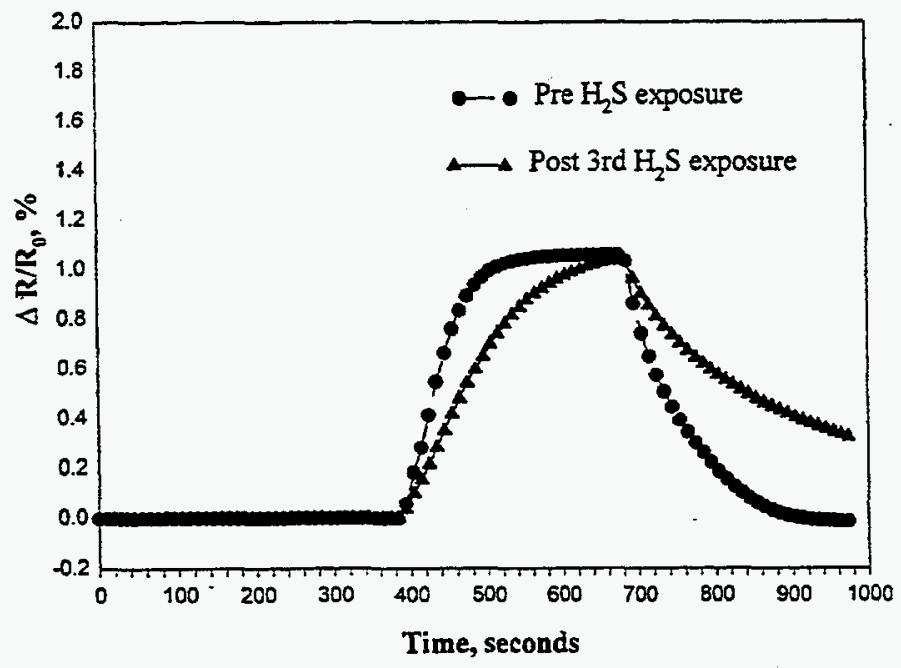



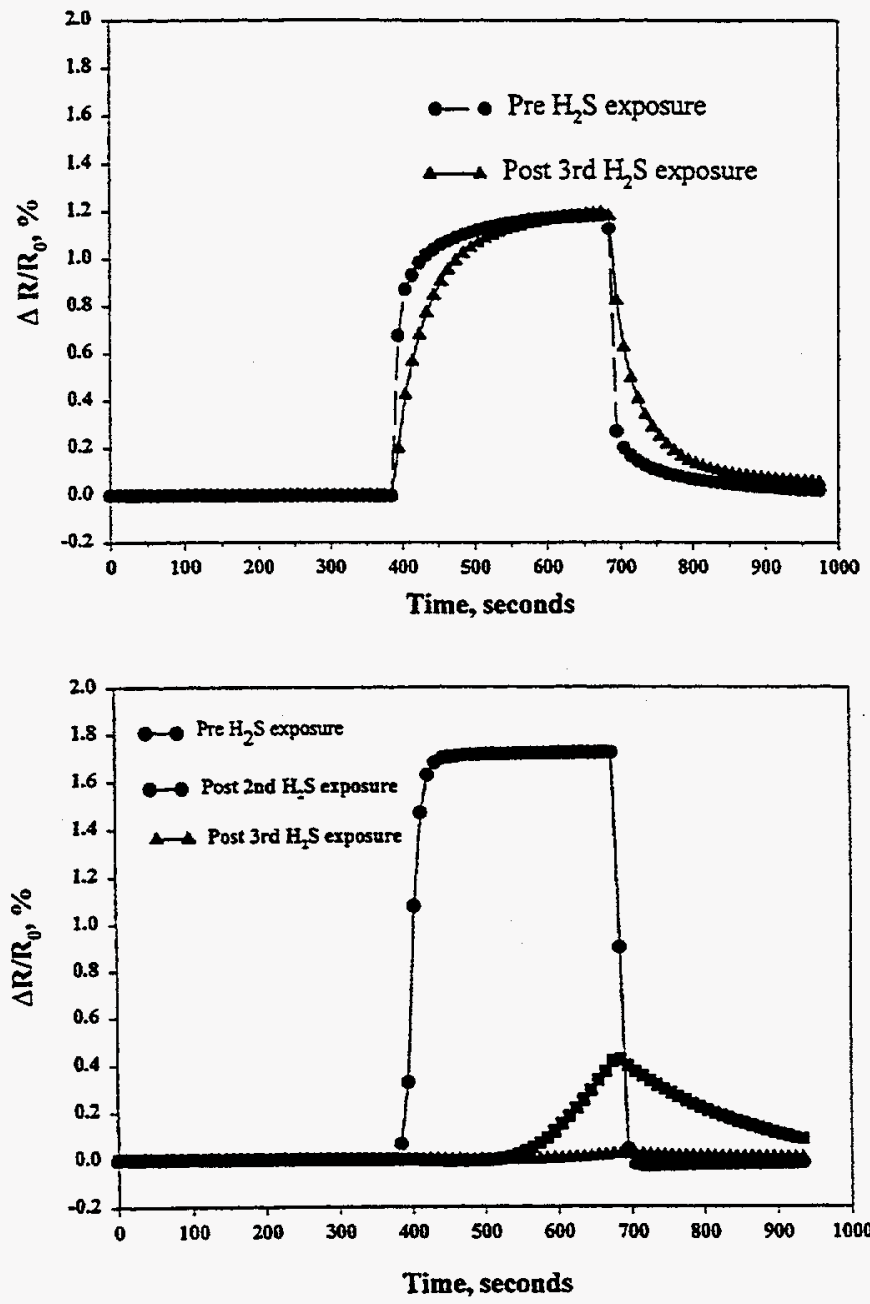

FIGURE 5 The effect of $\mathrm{H}_{2} \mathrm{~S}$ poisoning on coated versus uncoated films: (a) an uncoated sensor exposed to a pulse of $0.5 \% \mathrm{H}_{2}$ before and after exposures to $\mathrm{H}_{2} \mathrm{~S}(1000 \mathrm{ppm})$. The sensors were held at $34^{\circ} \mathrm{C}$ for both poisoning and testing. The size of the response is not effected but the rates for both pulse and purge are notably lowered for the uncoated sensor (9.3); (b) a coated sensor (16.1) of the same design as (a) in which the $\mathrm{H}_{2} \mathrm{~S}$ exposure has only a small effect; (c) another type of uncoated sensor wherein the $\mathrm{H}_{2} \mathrm{~S}$ exposure has a much more damaging effect. For the post $3^{\text {rd }}$ exposure, almost no response can be noted on this time scale 
Layer 2

The resulting titania-supported $\mathrm{Rh}$ thin film catalyst prepared from the DA-HTO powder were found to be ion-exchangeable and demonstrate similar activity as found for the ST-HTO Rh/HTO catalyst. The double alkoxide approach is greatly simplified in comparison to the ST-HTO synthetic route. Attempts to bypass the $\mathrm{Ti}\left(\mathrm{OPr}^{\mathrm{j}}\right)_{4}$ layer by depositing the $\left[\mathrm{NaTi}(\mathrm{OR})_{5}\right]_{\infty}$ directly onto the $\mathrm{A} 2 * *$ layer resulted in complete shut down of a working sensor. Therefore, the $\mathrm{A} 2^{* * / T i} /\left[\mathrm{NaTi}(\mathrm{OR})_{5}\right]_{\infty}$ modified sensor was produced and tested (see Figure 6a). Upon modification of the DA-HTO by ion-exchange to form a titania-supported $\mathrm{Rh}$ thin film catalyst, there is little change in the response of the sensor versus that "NaTi(OR $)_{5}$ " coating.

\section{Layer 3}

The final layer was deliberately deposited as a highly porous material and therefore had no further effect on the sensor. This layer completed the production of the CMS and tests are currently underway to determine the selectivity of this component. Figure $6 \mathrm{~b}$ shows the response of the CMS component.

\section{Conclusion}

We have clearly proven that the individual components of the CMS are integratable. The addition of the sol-gel A2** layer has yielded some surprisingly beneficial results. Sensors are often required to operate in chemically hostile environments for extended periods of time and we have quite unexpectantly found that the initial $\mathrm{A} 2 * *$ coating imparts poison resistance and protection from other hazards like condensed water and dust, while not degrading its performance. Furthermore, the large difference in response of the A2** coated and uncoated sensors allows us to employ a pattern recognition scheme to classify mixtures of $\mathrm{H}_{2} / \mathrm{O}_{2}$ and to extract the individual concentrations where both are unknown.

The generation of the double alkoxide $\left[\mathrm{NaTi}(\mathrm{OR})_{5}\right]_{\infty}$ solution involves a much less demanding solution synthesis in comparison to existing HTO catalyst precursors but has demonstrated similar catalytic 

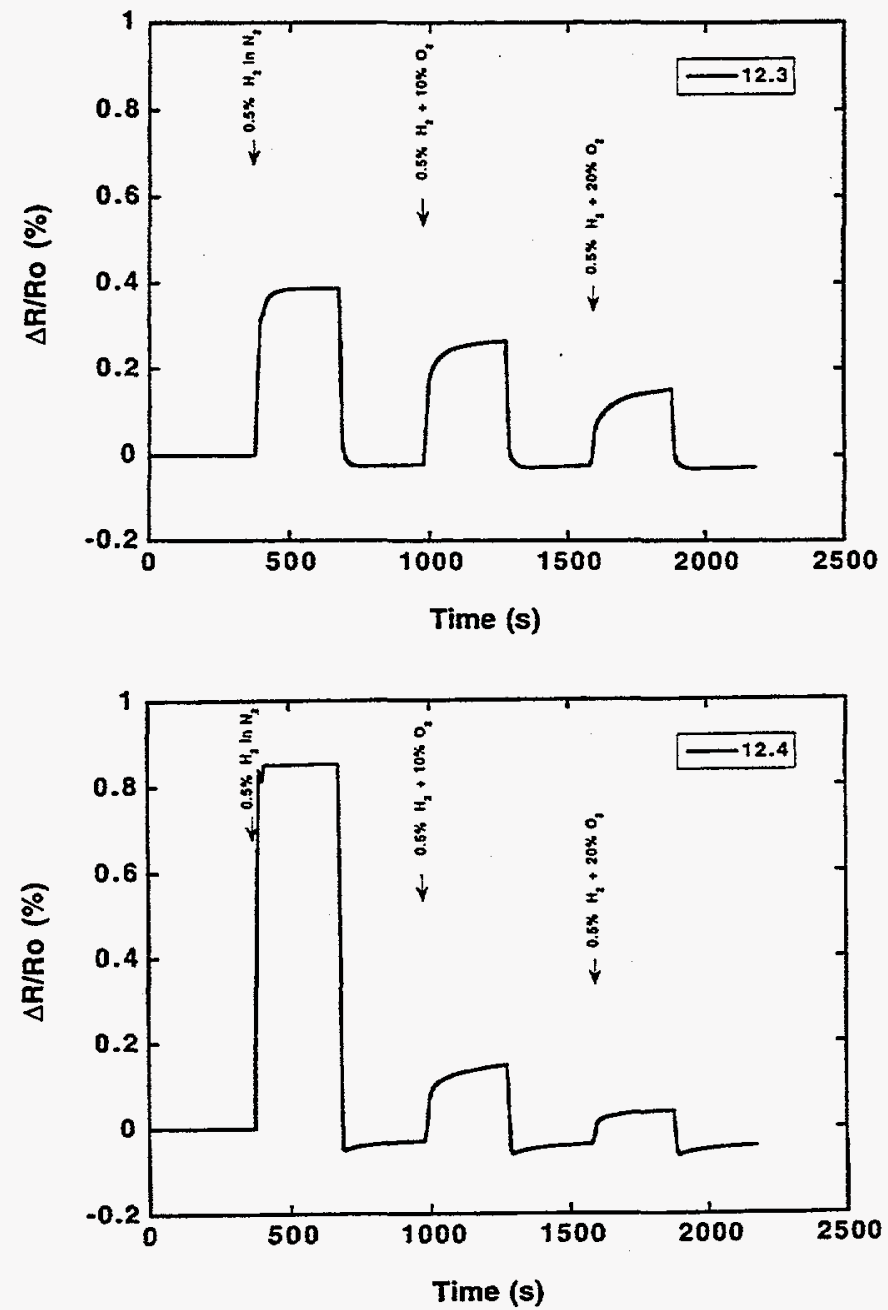

FIGURE 6 Response of $\mathrm{Pd} / \mathrm{Ni}$ sensor to $\mathrm{H}_{2} / \mathrm{O}_{2}$ mixtures for : (a) A2**/T1/catalyst layered sensor (12.3) and (b) A2**/T//catalyst/A2** layered (actual CMS component, 12.4). The sequence of exposures is the same as those noted for Figure 4. The data presented is typical of a post $150^{\circ} \mathrm{C}$ anneal where the sensor in $6 \mathrm{~b}$ shows the most catalytic activity for $\mathrm{O}_{2}$. This behavior was reproducible in several nuns for one week before higher temperature anneals 
behavior. The application of this layer to the $\mathrm{A} 2 * * / \mathrm{Ti}$ modified coating reduces the sensitivity of the sensor but does not shut it down. Further modifying the NaTi film by ion-exchange to make the titanium-supported $\mathrm{Rh}$ thin film catalyst does not further diminish the sensitivity of the sensor. The porous top layer also has little effect on the sensing ability of the $\mathrm{Pd} / \mathrm{Ni}$ sensor.

Currently we are pursing the functionality of the CMS component discussed above as a molecularly selective catalytically activated sensor. Initial attempts to selectively reduce an organic species will focus on dehydrogenation catalytic reactions.

\section{Acknowledgments}

This work was supported by the United States Department of Energy under contract number DE-AC04-94AL85000. Sandia is a multiprogram laboratory operated by Sandia Corporation, a Lockeed Martin Company, for the United States Department of Energy. The authors would like to thank Joseph W. Ziller (U.C.-Irvine) for single crystal X-ray diffraction sudies and the following Sandia National Laboratory employees for their assistance in the development of the CMS components: Catherine D. Buchheit (precursor synthesis/processing), Lindsey R. Evans (catalyst testing), Martin H. Gonzales (precursor synthesis/processing), Mark W. Jenkins (sensor testing), Linda I. McLaughlin (catalyst preparation), Ross Thomas (sensor testing), and Mark A. Rodriguez (XRD).

\section{References}

[1] Thomas, R. C.; Hughes, R. C., Internal Sandia National Laboratories report: SAND 96-1461J 1996.

[2] Thomas, R. C.; Hughes, R. C. JECS 1997, 144, 3245.

[3] Brinker, C. J.; Sehgal, R.; Hietala, S. L.; Deshpande, R.; Smith, C. M.; Loy, D. J. Membrane Sci. 1994, 94, 85.

[4] Brinker, C. J.; Raman, M. K.; Logan, M. N.; Sehgal, R.; Assink, R. A.; Hua, D. W.; Ward, T. L. J. Sol-Gel Sci. Tech. 1995, 4, 117.

[5] Sehgal, R. Ph. D. Thesis, University of New Mexico, 1996.

[6] Sault, A. G. J. Catal. 1995, 156, 154.

[7] Gardner, T. J.; Peden, C. H. F; Datye, A. K. Catal. Lett. 1992, 15, 111.

[8] Sault, A. G.; Peden, C. H. F.; Boespflug, E. P.J. Phys. Chem. 1994, 98, 1652.

[9] Stephens, H. P.; Dosch, R. G. In Preparation of Catalysts $V$; B. Delmon, P. Grange, P. A. Jacobs and G. Poncelet, Eds.; Elsevier Science Publishers, B. V.: Amsterdarn, 1987; pp 271.

[10] Boyle, T. J.; Bradley, D. C.; Hampden-Smith, M. J.; Patel, A.; Ziller, J. W. Inorg. Chem. 1995, 34,5893.

[11] Hughes, R. C.; Boyle, T. J.; Gardner, T. J.; Brinker, C. J.; Thomas, R. C. Digest of the 1997 International Conference on Solid State Sensors and Actuators, Transducers ' $97,1997,581$. 
[12] Boyle, T. J.; Alam, T. M.; Tafoya, C. J.; Ziller, J. W. Organometallics 1998,submitted.

[13] Boyle, T. J.; Alam, T. M.; Mechenbeir, E. R.; Scott, B.; Ziller, J. W. Inorg. Chem. $1997,36,3293$.

[14] Hampden-Smith, M. J.; Williams, D. S.; Rheingold, A. L. Inorg. Chem. 1990, 29, 4076.

[15] Boyle, T. J.; Alam, T. M.; Mechenbeir, E. R.; Scott, B.; Ziller, J. W. Abstracts of Papers of the American Chemical Sociery 1997, 213(pr.2), 693-INOR.

[16] Baes, C. F. J.; Mesmer, R. E. The Hydrolysis of Cations; John Wiley and Sons: New York, 1976.

[17] Boyle, T. J.; Dimos, D. B.; Alam, T. M.; Schwarzz, R. W.; Buchheit, C. D.; Sinclair, M. B. J. Mater. Res. 1997, 12, 1022.

[18] Bradley, D. C.; Mehrotra, R. C.; Gaur, D. P. Metal Alkoxides; Academic Press: New York, 1978.

[19] Hardcastle, F. D.; Peden, C. H. F.; Kidd, K. B. Unpublished results

[20] Kalakkad, D.; Anderson, S. L.; Logan, A. D.; Pena, J.; Braunschweig, E. J.; Peden, C. H. F.; Datye, A. K. J. Phys. Chem. 1993, 97, 1437.

[21] Yao, H. C.; Yao, Y. F. Y.; Otto, K.J. Catal. 179, 56, 21.

[22] Gardner, T. J.; I., M. L.; Evans, L. R.; Datye, A. K. Stud. Surf Sci. Catal. 1998, subminted.

[23] Samuel, J.; Hurd, A. J.; van Swol, F.; Douglas-Frink, L. J.; Brinker, D. J.; Contakes, S. C. Mater. Res. Soc. Symp. Proc. 1996, 431, 237.

[24] Samuel, J.; Brinker, C. J.; Douglas-Frink, L. J.; van Swol, F. Langmuir 1998, submitted.

[25] Maier, W. F.; Ko, H. C. Caralysis Today 1995, 25, 429.

[26] Hughes, R. C.; Moreno, D. J.; Jenkins, M. W.; Rodriguez, J. L. Technical Digest, Solid State Sensors and Actuator Workshop, Hilton Head Island, South Carolina, $1994,57$. 


\section{Distribution:}

$\begin{array}{lll}\text { Copies } & \text { Mai Stop } & \text { Recipient } \\ 1 & \text { MS9018 } & \text { Central Technical Files, 8940-2 } \\ 2 & \text { MS0899 } & \text { Technical Library, 4916 } \\ 1 & \text { MS0619 } & \text { Review and Approval Desk, 15102 for DOE/OSTI } \\ 1 & \text { MS0513 } & \text { Robert J. Eagan, 1000 } \\ 1 & \text { MS1425 } & \text { Kay Hays, 1800 } \\ 1 & \text { MS1434 } & \text { Gordon E. Pike, 1802 } \\ 1 & \text { MS1349 } & \text { William F. Hammetter, 1846 } \\ 1 & \text { MS1349 } & \text { Alan J. Hurd, 1841 } \\ 1 & \text { MS1425 } & \text { Stephen J. Martin, 1715 } \\ 1 & \text { MS1411 } & \text { Duane B. Dimos, 1831 } \\ 2 & \text { MS1349 } & \text { Timothy J. Boyle, 1846 } \\ 2 & \text { MS0710 } & \text { Timothy J. Gardner, 1841 } \\ 2 & \text { MS1425 } & \text { Robert C. Hughes, 1715 } \\ 1 & \text { MS1349 } & \text { C. Jeffery Brinker, 1831 } \\ 1 & \text { MS1425 } & \text { Gregory C. Frye-Mason, 1715 } \\ 1 & \text { MS0188 } & \text { LDRD Office, 4001 }\end{array}$




\section{DISTRIBUTION:}

1 MS $0188 \quad$ LDRD Office, 4001

$11002 \quad$ P. J. Eicker, 9600

$1 \quad 1006 \quad$ P. Garcia, 9671

$1 \quad 1006 \quad$ L. Meirans, 9671

$31006 \quad$ L. P. Ray, 9671

$11008 \quad$ J. C. Fahrenholtz, 9621

$151008 \quad$ P. G. Xavier, 9621

$1 \quad 1008 \quad$ T. R. Henry, 9621

$1 \quad 1008 \quad$ R. A. LaFarge, 9621

19018 Central Technical Files, 8940-2

$20899 \quad$ Technical Library, 4916

$10619 \quad$ Review \& Approval Desk, 15102

For DOE/OSTI

$10161 \quad$ Patent and Licensing Office, 11500 